\title{
ANALISIS IMPLEMENTASI INFRASTRUCTURE AS A SERVICE MENGGUNAKAN UBUNTU CLOUD INFRASTRUKTUR
}

Norma Fitra Pusta Rahma ${ }^{1)}$, Adian Fatchur Rochim, S.T., M.T. ${ }^{2)}$, Eko Didik Widianto, S.T., M.T. ${ }^{2)}$ Jurusan Teknik Sistem Komputer, Fakultas Teknik, Universitas Diponegoro, Jln. Prof. Sudharto, Tembalang, Semarang, Indonesia

email : noe_norma@yahoo.com

\begin{abstract}
ABSTRAK
Semakin canggih dan berkembangnya teknologi informasi di berbagai aspek kehidupan, meniscayakan perguruan tinggi sebagai institusi pengembang ilmu pengetahuan dan teknologi (IPTEK) untuk merespon positif. Hal ini akan berdampak juga dalam perkembangan perangkar keras yang secara tidak langsung harus mengikuti perkembangan teknologi informasi yang ada sehingga akan dilakukan penambahan perangkat yang akan menyebabkan penambahan biaya untuk membeli perangkat yang baru. Hal tersebut dapat dipenuhi dengan menggunakan teknologi cloud computing. Cloud computing merupakan model komputasi, dimana sumber daya seperti daya komputasi, penyimpanan, jaringan dan perangkat lunak disediakan sebagai laayanan di internet. Sumber daya komputasi tersebut dapat dipenuhi oleh layanan layanan cloud Infrastructure as a Service (IaaS).Infrastructure as a Service tersebut dibangun dengan menngunakan Infrastruktur Cloud Ubuntu. Sistem Operasi yang digunakan adalah Ubuntu Server 12.04 LTS dan serta perangkat lunak yang digunakan untuk membangun infrastruktur adalah OpenStack versi essex. Hasil dari tugas akhir ini adalah terciptanya mesin virtual berdasarkan spesifikasi CPU, memory, dan disk yang dipilih melalui flavor yaitu m1.tiny dengan spesifikasi memori $512 \mathrm{MB}$, disk $O \mathrm{~GB}$, ephemeral $O \mathrm{~GB}, v C P U$ 1. Image yang digunakan pada instance adalahsServer Ubuntu 12.04.3 LTS. Kecepatan CPU yang didapat pada mesin virtual tersebut adalah 3000,106 MHz. Penggunaan CPU pada instance dengan nama "webserver" meliputi 0,3\% dengan sisa 0,97\%, Memori 422764k dari total keseluruhan 503496.
\end{abstract}

Kata Kunci : Cloud Computing, IaaS, OpenStack, Mesin Virtual.

\section{PENDAHULUAN}

\subsection{Latar Belakang}

Semakin canggih dan terus berkembangnya teknologi informasi di berbagai aspek kehidupan, meniscayakan perguruan tinggi sebagai institusi pengembang ilmu pengetahuan dan teknologi (IPTEK) untuk merespon secara postif. Di samping sebagai pengembang IPTEK, perguruan tinggi dalam operasional kegiatannya juga membutuhkan teknologi khususnya teknologi informasi. Agar tidak ketinggalan dalam penguasaan dan penggunaan teknologi, khususnya teknologi infomasi, maka perguruan tinggi harus senantiasa mengikuti perkembangan IPTEK.

Perangkat keras akan menjadi salah satu faktor kendala ketika sistem akan dilakukan upgrade. Karena dengan melakukan upgrade pada sistem akan semakin baik sebuah sistem tersebut maka dari itu harus didukung dengan perangkat keras yang sesuai. Dapat disimpulkan bahwa semakin baik sebuah sistem maka perangkat keras dari sistem tersebut harus baik pula yang berarti dilakukan penambahan perangkat. Penambahan perangkat ini akan menyebabkan penambahan biaya untuk membeli perangkat yang baru.

Pemenuhan kebutuhan perangkat keras tersebut dapat dilakukan secara virtual dengan menggunakan teknologi cloud computing. Cloud computing merupakan sebuah model komputasi dimana sumber daya seperti daya komputasi, penyimpanan, jaringan dan perangkat lunak disediakan sebagai layanan di internet.

\subsection{Tujuan}

Tujuan atau hasil yang ingin dicapai dalam penelitian ini adalah :

1. Merancang dan mengimplementasikan OpenStack sebagai infrastruktur cloud.

2. Menguji infrastruktur cloud untuk Server Ubuntu 12.04 . 


\subsection{Pembatasan Masalah}

Batasan masalah dalam penelitian ini adalah :

1. Sistem ini dibangun dari 2 buah komputer, 1 buah sebagai server dan 1 buah sebagai klien.

2. Server menggunakan sistem operasi Linux distro Ubuntu 12.04 LTS.

3. Komputer klien menggunakan sistem operasi windows dengan aplikasi putty sebagai remote server.

4. Perangkat lunak OpenStack digunakan untuk membangun IaaS.

5. Image virtual Ubuntu 12.04 yang digunakan untuk membangun instance.

\section{LANDASAN TEORI}

\subsection{Cloud Computing}

Cloud Computing adalah sebuah model komputasi dimana sumber daya seperti daya komputasi, penyimpanan, jaringan dan perangkat lunak disediakan sebagai layanan di internet (Buyya, James \& Goscinski, 2011).

2.2 Layanan Cloud Computing (IaaS)

Infrastructure as a Service

(IaaS) adalah bagian sistem dalam cloud computing yang menyediakan seluruh kebutuhan infrastruktur mulai dari penyimpanan, perangkat keras dan semua infrastruktur tersebut telah disediakan oleh provider cloud.

\subsection{Teknologi Virtualisasi}

Virtualisasi diartikan sebagai pembuatan suatu bentuk atau versi virtual dari sesuatu yang bersifat fisik, misalnya sistem operasi, perangkat penyimpanan data atau sumber daya jaringan. Dengan virtualisasi, maka sebuah komputer (fisik) bisa menjalankan banyak komputer virtual sekaligus pada saat yang bersamaan.

Virtualisasi memungkinkan adanya skalabilitas dan elastisitas yang tidak terjadi pada teknologi tradisional. Dari segi elastisitas, teknologi virtualisasi ini memberi keluasan pengguna layanan untuk dapat meningkatkan kapasitas layanan yang ingin dimilikinya (Armbrust, et al., 2009). Dari segi skalabilitas, dengan virtualisasi ini nantinya pengguna dapat dengan mudah meningkatkan kinerja sistem secara berangsur-angsur sesuai dengan beban pekerjaan dengan hanya mengurangi ataupun menambahkan sejumlah prosesor secara virtual sesuai dengan kebutuhan.

\subsection{OpenStack}

OpenStack merupakan perangkat lunak berbasis open source dalam cloud computing yang berorientasi di bidang Infrastructure as s Service (IaaS).

Ada lima servis utama yang terdapat pada OpenStack yaitu : Nova, Swift, Glance, Keystone dan Horizon.

1. OpenStack Compute Infrastructure (Nova) adalah perangkat lunak open source yang di desain untuk mengelola jaringan-jaringan dengan skala besar, virtual mesin serta menciptakan platform yang skalabel untuk cloud computing.

2. OpenStack Object orage Infrastructure (Swift) adalah perangkat lunak open source untuk membuat penyimpanan data yang bersifat skalabel serta redundant/bercabang dengan menggunakan sistem cluster server untuk menyimpan data-data dalam ukuran terabytes atau bahkan petabytes.

3. OpenStack Image Service (Glance) adalah satu produk dari OpenStack yang digunakan untuk layanan virtual disk images.

4. Keystone merupakan layanan dari Openstack yang menyediakan layanan Identity, Token, Catalog dan Policy services digunakan oleh proyek-proyek di dalam keluarga OpenStack.

5. Horizon atau disebut juga dengan dashboard berbasis web yang digunakan untuk mengatur atau mengelola layanan Openstack.

\subsection{Virtual Machine}

Virtual machine (VM) atau mesin virtual mengemulasikan keseluruhan sistem perangkat keras, mulai dari prosessor sampai network card, memungkinkan sistem operasi yang berbeda untuk berjalan secara simultan.

\subsection{Virtual Disk}

Virtual Disk digunakan untuk boot dan untuk menjalankan sistem operasi. Disk virtual dapat menjadi bagian dari template yang dibuat sebagai bagian dari proses pembuatan mesin virtual dan dapat dibuat secara terpisah sebagai media penyimpanan.

\subsection{Image Virtual}

Image virtual merupakan berupa file tunggal yang berisi virtual disk yang berupa sistem operasi yang bootable digunakan untuk instalasi virtual mesin. 


\subsection{Ubuntu}

Ubuntu merupakan salah satu distribusi Linux yang berbasiskan Debian dan didistribusikan sebagai software bebas.

\section{PERANCANGAN SISTEM}

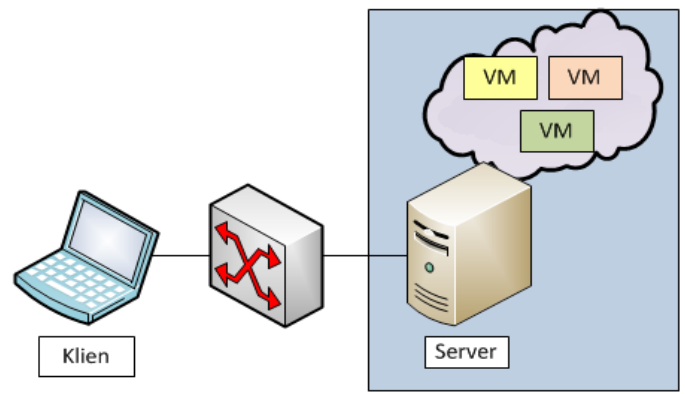

Gambar 1 Skema perancangan sistem

Arsitektur yang digunakan dalam pembangunan infrastruktur cloud adalah single node yaitu dengan menggunakan satu buah server. Server tersebut akan menjalankan semua servis dari openstack dan juga semua instance. Terdapat tiga bagian dengan fungsi yang berbeda ditunjukkan pada Gambar 1. Server difungsikan sebagai penyedia cloud. Klien digunakan untuk membangun image dan mengelola infrastruktur cloud berbasis web. Diantara keduanya dihubungkan sebuah switch.

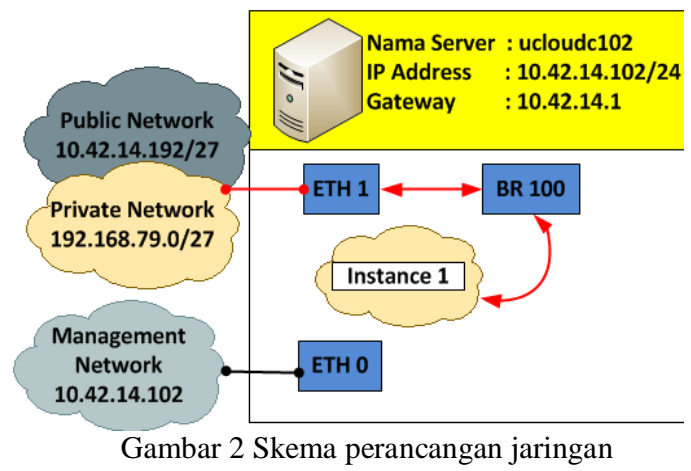

Gambar 2 menunjukkan perancangan jaringan yang ada pada host dan instance. Host terhubung dengan eth 0 dan mempunyai IP address statik 10.42.14.102. Instance terhubung dengan eth1 dan memiliki dua tipe IP address, yaitu IP publik (10.42.14.192/27) yang digunakan untuk komunikasi antara instance dengan jaringan luar dan IP privat (192.168.79.0/27) digunakan untuk berkomunikasi antar instance. Semua instance terhubung dengan bridge yang sama.

Kebutuhan perangkat keras pada tugas akhir ini terdiri dari server, switch, kabel UTP, konektor RJ45, NIC (Network Interface), hub, dan koneksi internet.

Tabel 1 Spesifikasi teknis server Openstack

\begin{tabular}{|l|l|}
\hline Keterangan & \multicolumn{1}{|c|}{ Spesifikasi Teknis } \\
\hline Prosesor & $\begin{array}{l}\text { Pentium (R) DualCore CPU E5700 } \\
\text { @ 3.00 GHz }\end{array}$ \\
\hline RAM & $2 \mathrm{G}$ \\
\hline Hard disk & $\begin{array}{l}\text { 92 GB } \\
\text { Intel Cooperation N10/ICH7 } \\
\text { Family SATA Controller }\end{array}$ \\
\hline NIC & $\begin{array}{l}\text { Realtek Semiconductor Co. Ltd } \\
\text { RTL8101E/ RTL8102E PCI } \\
\text { Express Fast Ehernet Controller } \\
\text { (Rev 02) }\end{array}$ \\
\hline VGA & $\begin{array}{l}\text { Intel Corporation 4 series Chipset } \\
\text { Integrated Graphics Controller }\end{array}$ \\
\hline
\end{tabular}

Perangkat keras yang digunakan dengan sepesifikasi pada Tabel 1 dikarenakan virtualisasi pada hypervisior KVM membutuhkan mesin dengan prosesor 64-bit dan IntelVT. Pada virtualisasi membutuhkan RAM yang besar untuk dapat menjalankan beberapa instance.

Tabel 2 Spesifikasi teknis server Openstack

\begin{tabular}{|c|c|}
\hline Keterangan & Spesifikasi Teknis \\
\hline $\begin{array}{l}\text { Konfigurasi } \\
\text { Openstack }\end{array}$ & $\begin{array}{l}\text { Semua komponen Openstack } \\
\text { termasuk nova-compute. } \\
\text { yaitu nova, glance, keystone, dan } \\
\text { horizon. }\end{array}$ \\
\hline NIC & Eth0-jaringan lokal \\
\hline IP address & Eth0-10.42.14.102 \\
\hline Hostname & localadmin \\
\hline DNS server & 10.42 .52 .1 \\
\hline Gateway IP & 10.42 .14 .1 \\
\hline $\begin{array}{l}\text { Tabel } 2 \\
\text { mengenai } \\
\text { dilakukan p } \\
\text { Penggunaan } \\
\text { dengan alok } \\
\text { jaringan kom }\end{array}$ & $\begin{array}{l}\text { nerupakan spesifikasi teknis } \\
\text { onfigurasi jaringan yang } \\
\text { da perangkat keras (host). } \\
\text { alamat IP akan disesuaikan } \\
\text { si alamat IP yang ada di } \\
\text { uter UNDIP. }\end{array}$ \\
\hline
\end{tabular}

Tabel 3 Teknologi yang digunakan dalam membangun cloud

\begin{tabular}{|c|c|}
\hline Teknologi & Implementasi \\
\hline Message queue & RabbitMQ 2.7.1.0 \\
\hline \multirow{2}{*}{ Virtualisasi } & Libvirt \\
\cline { 2 - 2 } Basis data & KVM \\
\cline { 2 - 2 } & MySQL 5.5.31 \\
\hline Web Server & Apache 2.2.22 \\
\hline $\begin{array}{l}\text { Network } \\
\text { manager }\end{array}$ & FlatDHCP \\
\hline
\end{tabular}


Pada tabel 3 merupakan serangkaian teknologi yang dipakai dalam pembuatan infrastruktur cloud. tekhnologi tersebut dibangun di atas host.

Tabel 4 Spesifikasi flavor

\begin{tabular}{|c|l|l|l|l|l|l|l|}
\hline ID & \multicolumn{1}{|c|}{ Nama } & $\begin{array}{c}\text { Memori } \\
(\mathrm{Mb})\end{array}$ & \multicolumn{1}{|c|}{ Disk } & $\begin{array}{c}\text { Ephe- } \\
\text { meral }\end{array}$ & Swap & VCPU & RXTX_Factor \\
\hline 1 & m1.tiny & 512 & 0 & 0 & & 1 & 1.0 \\
\hline 2 & m1.small & 2048 & 10 & 20 & & 1 & 1.0 \\
\hline 3 & m1.medium & 4096 & 10 & 40 & & 2 & 1.0 \\
\hline 4 & m1.large & 8192 & 10 & 80 & & 4 & 1.0 \\
\hline 5 & m1.xlarge & 16384 & 10 & 160 & & 8 & 1.0 \\
\hline
\end{tabular}

Tabel 4 menjelaskan serangkaian flavor yang di bangun oleh admin yang memiliki lima flavor dengan spesifikasi tertentu. Flavor digunakan untuk menetepkan berapa jumlah CPU virtual yang digunakan instance dan jumlah RAM-nya, disk ephermeral dan lain sebagainya.

Tabel 5 Spesifikasi perangkat lunak yang digunakan untuk mesin virtual

\begin{tabular}{|l|l|}
\hline \multicolumn{1}{|c|}{ Keterangan } & \multicolumn{1}{c|}{ Spesifikasi Teknis } \\
\hline Sistem Operasi & $\begin{array}{l}\text { Ubuntu Server 12.04 LTS } \\
\text { 64bit }\end{array}$ \\
\hline Basis Data & MySQL \\
\hline Apache & 2.2 .22 \\
\hline Format image & Qcow2 \\
\hline
\end{tabular}

Tabel 5 memuat spesifikasi perangkat lunak yang digunakan ketika mesin virtual berhasil dibangun

\section{IMPLEMENTASI, PENGUJIAN DAN ANALISA SISTEM}

\subsection{Implementasi}

Setelah semua konfigurasi dilakukan pada server host, maka selanjutnya memanggil servis pada nova yaitu memanggil perintah :

$$
\text { nova-manage service-list }
$$

Perintah tersebut digunakan untuk mengetahui servis yang aktif pada layanan cloud. servis tersebut terdiri dari nova-cert, nova-compute, nova-consoleauth, novanetwork, nova-volume dan nova scheduler.

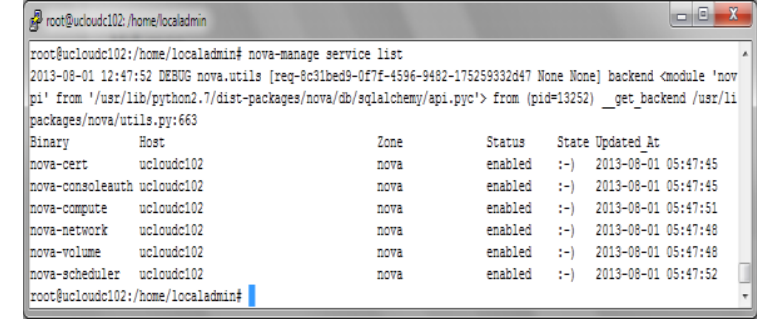

Gambar 3 Tampilan servis untuk nova

Gambar 3 diatas merupakan tampilan servis-servis yang bekerja pada cloud. Pada bagian state muncul tanda seperti ikon senyum (:) pada masing-masing servis, hal tersebut menandakan bahwa servis tersebut dalam keadaan up dan sedang berjalan dengan baik.

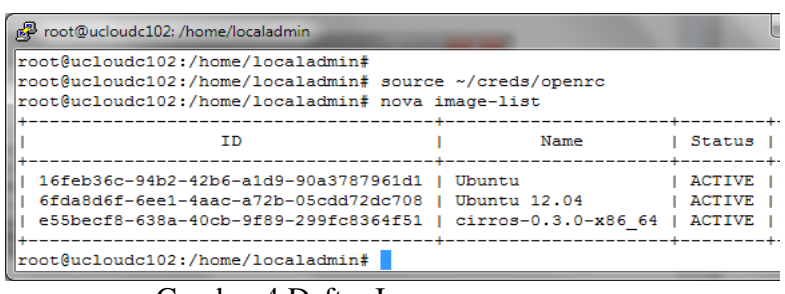

Gambar 4 Daftar Image

Image yang akan digunakan adalah "Ubuntu 12.04" dengan ID "6fda8d6f-6ee14aac-a72b-05cdd72dc708". Image tersebut berisi sistem operasi Ubuntu Server 12.04.3 LTS.

\subsection{Pengujian}

Pengujian dilakukan dengan membangun mesin virtual yang dilakukan di dashboard. 


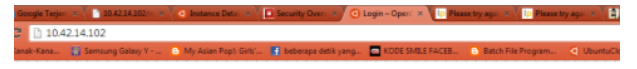

\section{SISKOMCLOUD.}

Log In

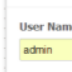

athin
Password
$-\cdots-$

Gambar 5 merupakan tampilan awal login pada dashboard/horizon. Dashboard akan menampilkan layanan-layanan yang disediakan oleh admin. Username dan password yang dimasukkan merupakan hasil konfigurasi pada indentity/keystone.

Username : admin

Password : admin

Gambar 5Tampilan awal dashboard

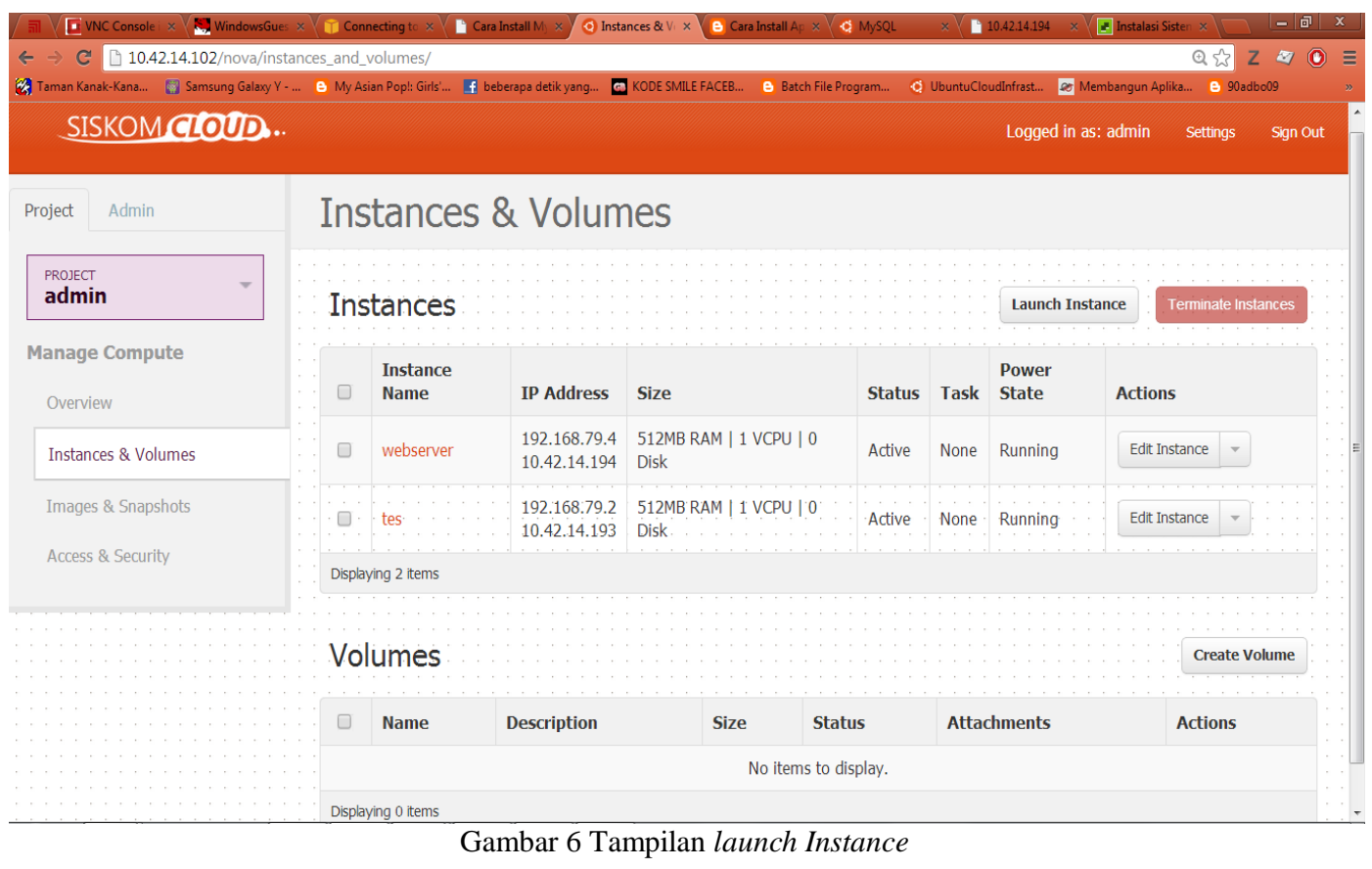

Gambar 6 merupakan tampilan instance yang dibangun oleh admin. Instance yang dibangun dengan nama webserver.

\subsection{Analisa Sistem}

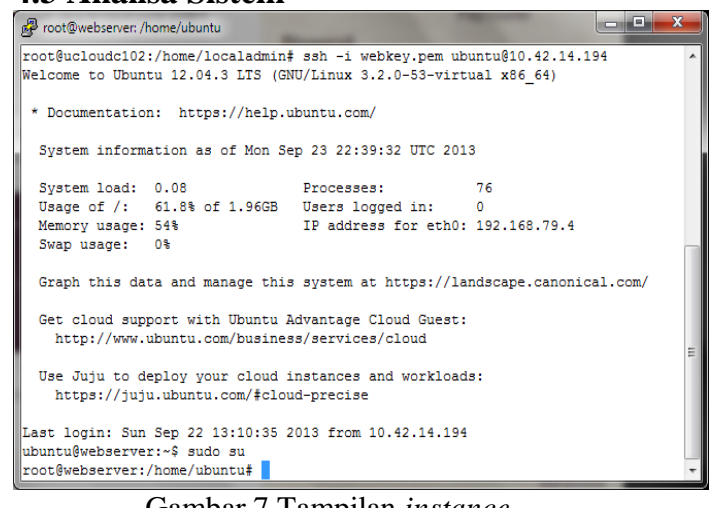

Gambar 7 Tampilan instance
Gambar diatas menunjukkan user telah berhasil login ke dalam instance sebagai user root bernama webserber. Perintah yang digunakan untuk ssh adalah ssh -i webkey pem

ubuntu@10.42.14.194. Ubuntu merupakan user pada instance dan 10.42.14.194 merupakan ip publik dari instance bernama ubuntu. Setelah berhasil ssh ke instance tersebut, dapat dilihat Ip privat yang didapat oleh instance "webserver" yaitu 192.168.79.4.

Flavor yang digunakan untuk instance dengan nama "webserver" adalah m1.tiny. Spesifikasi flavor tersebut adalah memori $512 \mathrm{MB}$, disk $0 \mathrm{~GB}$, Ephemeral 0 GB, swap 0 GB dan jumlah vCPU 1 core. 


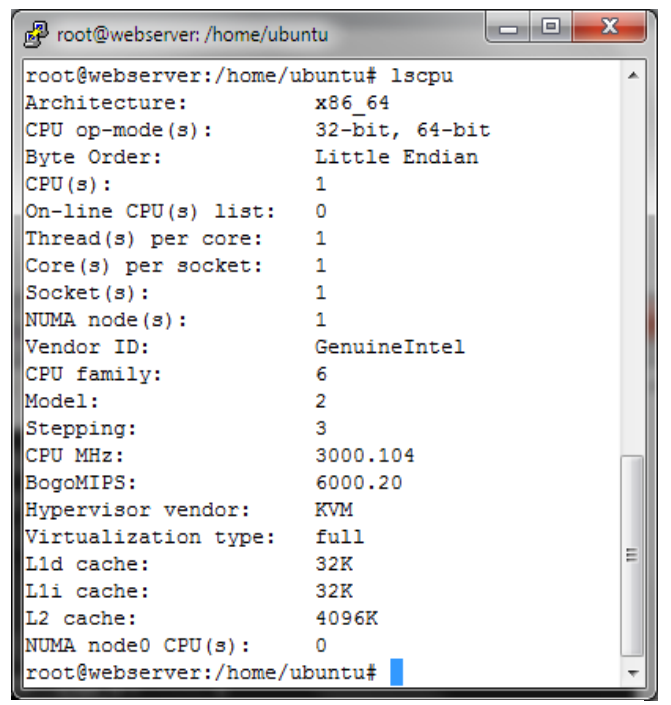

Gambar 8 Tampilan informasi arsitektur CPU yang digunakan pada instance

Gambar 8 menampilkan informasi arsitektur CPU yang digunakan oleh sistem dengan menggunakan perintah Iscpu. CPU yang digunakan user pada instance "webserver" adalah satu buah CPU 64-bit. Kecepatan CPU yang dimiliki adalah 3000,106 MHz.

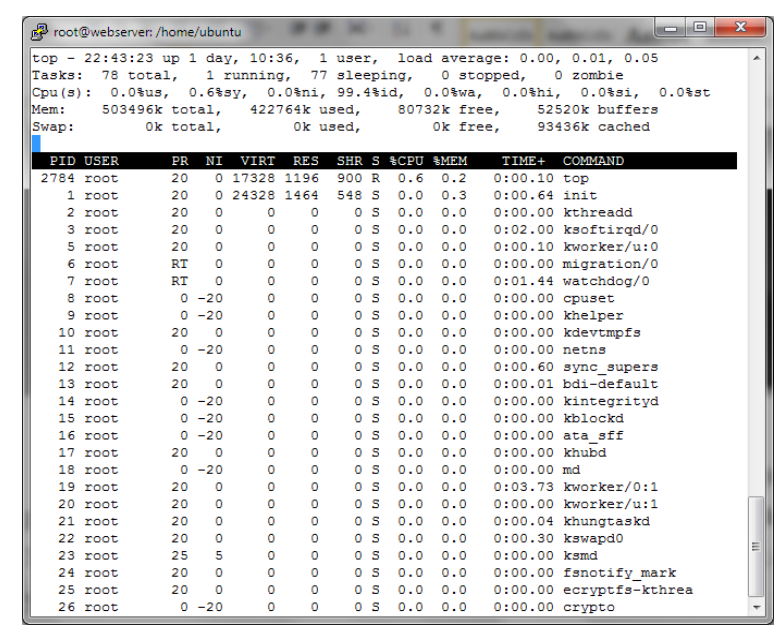

Gambar 9 Tampilan penggunaan cpu dan memori

Pada gambar 4.55 dengan menggunakan perintah CLI \$ top menunjukkan penggunaan CPU pada instance meliputi $0,3 \%$ dengan sisa $99,7 \%$, Memori $422764 \mathrm{k}$ dari total keseluruhan 503496.

Pengujian yang dilakukan menunjukkan bahwa instance dengan nama "webserver" telah berhasil dibangun sesuai dengan flavor yang dipilih pada saat akan membangun mesin virtual yaitu flavor m1.tiny.
Deskripsi dari flavor m1.tiny adalah memori 512Mb, Disk 0, Ephemeral 0, VCPU 1.0, dan swap 0 .

\section{PENUTUP}

\subsection{Simpulan}

Penulis menyimpulkan dari hasil analisa dan pembahasan bahwa :

1. Infrastruktur cloud berhasil dirancang dan diimplementasikan dengan menggunakan OpenStack versi Essex menggunakan satu buah server (single host) dengan sistem operasi Ubuntu 12.04 LTS.

2. Sumber daya komputasi dapat dibangun sesuai dengan permintaan user secara ondemand dengan memilih flavor yang tersedia dari ukuran m1.tiny, m2.small, m3.medium, m4.large dan m5.xlarge

3. Image yang dibuat menggunakan sistem operasi Ubuntu 12.04.3 LTS dengan format qcow2.

4. Image dapat digunakan kembali untuk membangun instance walaupun sebelumnya sudah pernah digunakan untuk membangun instance.

5. Sebuah mesin virtual telah berhasil dibangun dengan menggunakan flavor bernama m1.tiny (dengan spesifikasi Memori 512 MB, Disk 0 GB, Ephemeral $0 \mathrm{~GB}, \mathrm{vCPU} 1)$.

6. CPU yang digunakan user pada instance ini adalah satu buah CPU 64-bit .

7. Kecepatan CPU yang dimiliki instance adalah 3000,106 MHz.

8. Penggunaan CPU pada instance dengan nama "webserver" meliputi 0,3\% dengan sisa 99,7\%, Memori $422764 \mathrm{~K}$ dari total keseluruhan $503496 \mathrm{~K}$.

\subsection{Saran}

Adapun saran yang dapat diberikan sehubungan dengan pelaksanaan penelitian ini adalah :

1. Infrastruktur cloud ini dapat dikembangkan lagi dengan menggunakan mesin virtual yang telah dibuat menjadi sebuah layanan berbasis aplikasi.

2. Dalam pengembangannya, infrastruktur cloud dapat dibangun pada multi server.

3. Teknologi cloud computing dapat lebih dioptimalkan pada organisasi yang mempunyai anggaran biaya sedikit. 
4. Penggunaan teknologi cloud computing juga dapat digunakan untuk perguruan tinggi guna untuk kebutuhan riser mahasiswa.

\section{DAFTAR PUSTAKA}

Armbrust, M., A. Fox , R. Griffith, A.D. Joseph, R. Katz dan A. Konwinski, 2009, Above the Cloud: A Beekeley View of Cloud Computing, UC Berkeley Reliable Adaptive Distributed Systems Laboratory, pp. 10-12.

Atmono, Widi. M. Hariadi dan Christyowidiasmoro, 2012, Desain dan Implementasi Cloud Computing Menggunakan Nimbus, Institute Teknologi Sepuluh Nopember: Surabaya.

Buyya, R., James B. dan Goscinski A., 2011, Cloud Computing: Principle and Paradigm, United Stated of America : John Wiley and Sons, Inc.

Nurmi, D., Wolski R., Grzegorczyk C., Obertelli G., Soman S., Youseff L. dan D. Zagorodnov, 2009, The Eucalyptus open-source cloudcomputing system, in Proceedings of IEEE/ACM International Symposium on Cluster Computing and the Grid (CCGrid 2009), Shanghai, China, pp. 124-131, University of California, Santa Barbara.

Tanggal Akses : 7 maret 2013 http://vgrads.rice.edu/publications /pdfs/eucalyptus-ccgrid2009.pdf/

Goyal, Vikas, 2012, Review: Layers Arhitecture Of Cloud Computing. International Journal of Computing and Business Research.

Tanggal akses : 1 Juli 2013

http://www.researchmanuscripts.c om/isociety2012/53.pdf

Jackson, K., 2012, Openstack Cloud Computing Cookbook, Birmingham: Packt Publishing Ltd.

Jha, A., D. J. Murari, K. Raju, M. dan Yogesh, G.. 2012, Openstack
Beginner's Guide for UbuntuPrecise, CSS Corp.

Judith, H., Robin, B. dan Marcia, K., 2010, Cloud Computing for Dummies: HP Special Edition, Indiana: Wiley Publishing, Inc.

Ken, Pepple, 2011, Deploying Openstack, United States of America: O'Reilly Meida, In

Liu, Fang, 2011, NIST Cloud Computing Reference Architecture, U.S. Departement of Commerce. Tanggal akses : 16 April 2013 http://www.cloudcredential.org/i mages/pdf_files/nist\%20reference $\% 20$ architecture.pdf

Mell, P. dan Grance T., 2012, The NIST Definition of Cloud Computing, U.S. Departement of Commerce. Tanggal Akses : 27 April 2013 http://csrc.nist.gov/publications/ni stpubs/800-145/SP800-145.pdf

Purbo, Onno W., 2011, Petunjuk Praktis : Cloud Computing Menggunakan Open Source, Jakarta.

Supriadi, M. dan Achmad Iffan Marzuq, 2013, Analisis Performance Cloud Computing berbasis Platform as A Service (PaaS) dengan Eucalyptus System dan Open Stack pada Ubuntu Server, Sekolah Tinggi Ilmu Komunikasi : Surabaya.

Wahana Komputer, 2011, Administrasi Jaringan dengan Linux Ubuntu 11, ANDI : Yogyakarta.

Youseff, Lamia, Maria Butrico dan Dilma Da Silva, 2008, Toward a Unified Ontology of Cloud Computing, University of California: Santa Barbara.

Tanggal akses : 15 Maret 2013 http://dosen.narotama.ac.id/wpcontent/uploads/2012/01/Towarda-Unified-Ontology-of-CloudComputing.pdf 
BIODATA

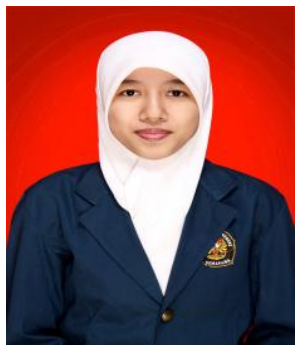

Norma Fitra Pusta

Rahma, lahir di

Kendal, 01 mei 1990.

Menjalani pendidikan

di Taman Kanak-

kanak I'anatut

Tholibin, SDN 3

Ngembal Rejo,

Sekolah Menengah

Pertama Negeri 2 Kudus, Sekolah Menengah Atas Negeri 1 Bae. Dan sekarang tengah menyelesaikan pendidikan Strata Satu di Jurusan Teknik Sistem Komputer, Universitas Diponegoro, Semarang, Indonesia Angkatan Tahun 2008.
Mengetahui/Mengesahkan

Dosen Pembimbing I

Adian Fatchur Rochim, S.T., M.T. NIP 196310281993031002

Mengetahui/Mengesahkan Dosen Pembimbing II

Eko Didik Widianto, S.T., M.T. NIP 197706152008011011 